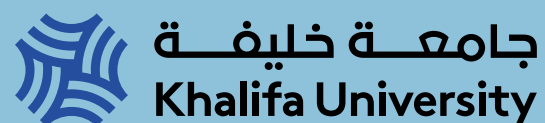

\title{
Opportunities for Natural Gas Infrastructure and Trade in the GCC
}




\section{About KAPSARC}

The King Abdullah Petroleum Studies and Research Center (KAPSARC) is a non-profit global institution dedicated to independent research into energy economics, policy, technology and the environment across all types of energy. KAPSARC's mandate is to advance the understanding of energy challenges and opportunities facing the world today and tomorrow, through unbiased, independent, and high-caliber research for the benefit of society. KAPSARC is located in Riyadh, Saudi Arabia.

This publication is also available in Arabic.

\section{Legal Notice}

(C) Copyright 2020 King Abdullah Petroleum Studies and Research Center ("KAPSARC"). This Document (and any information, data or materials contained therein) (the "Document") shall not be used without the proper attribution to KAPSARC. The Document shall not be reproduced, in whole or in part, without the written permission of KAPSARC. KAPSARC makes no warranty, representation or undertaking whether expressed or implied, nor does it assume any legal liability, whether direct or indirect, or responsibility for the accuracy, completeness, or usefulness of any information that is contained in the Document. Nothing in the Document constitutes or shall be implied to constitute advice, recommendation or option. The views and opinions expressed in this publication are those of the authors and do not necessarily reflect the official views or position of KAPSARC. 


\section{Key Points}

ith natural gas developments underway in Gulf Cooperation Council (GCC) countries, the question arises as to whether regional coordination, in the form of a cross-border pipeline network, can pave the way for a more efficient monetization of their gas resources. The answer depends on the respective commercial, regulatory and legal frameworks of these countries. Given the common interests of GCC countries, a pan-GCC gas grid may bring mutual benefits. We find that:

Energy price reforms and efficiency measures are expected to reduce natural gas demand growth in GCC countries. However, natural gas still has a significant role to play in managing renewable energy variability, while also supporting industrialization efforts and emerging areas such as liquefied natural gas (LNG) bunkering and clean hydrogen production.

Natural gas investments in the Middle East and North Africa (MENA) region are expected to continue in the next five years, despite the impact of the COVID-19 pandemic. Most of these projects are spearheaded by GCC countries.

Enhancing gas security, boosting diversification efforts, and improving efficiency are all supporting reasons for GCC gas grid integration. However, the barriers to trade among GCC countries, especially the non-commercial aspects, need to be addressed.

Linking the GCC countries' industrial and electricity market policies to their natural gas development is key to creating a demand pull and enabling GCC trade. Utilizing existing GCC infrastructure, such as the electric power GCC Interconnector, will also help in this regard. 


\section{Summary}

D espite the common interests, markets, and economic policies among Gulf Cooperation Council (GCC) countries, their energy cooperation has been modest. GCC countries hold $20 \%$ of the world's gas reserves. The Dolphin gas pipeline, connecting Qatar to the United Arab Emirates (UAE) and Oman, is currently the only GCC cross-border pipeline. As the experiences of North America and Europe demonstrate, there can be many benefits to expanding the GCC's gas pipeline grid, with the gas networks in both North America and Europe increasingly becoming more integrated and resilient. Gas cooperation among GCC countries can enhance their gas security, boost their diversification efforts, and yield economic improvements through efficiency gains. It could even cement the GCC as a preeminent energy hub. KAPSARC's modeling simulations have shown that an integrated GCC pipeline grid could have generated $\$ 400$ million of economic gains for GCC countries in 2018, under current gas pricing policies. The gains are driven by substituting regional liquefied natural gas (LNG) imports with cross-border pipeline gas trade at lower supply costs. This supports efficiency gains in power and water generation, including the substitution of crude oil. The analysis also highlights the role of a pipeline network in driving regional fuel price integration among the GCC's national power sectors. However, their demand development, lack of price integration, and geopolitics can and have constrained efforts to enhance cross-border gas trade.

One of the successful energy coordination efforts among GCC countries has been electric power integration via the GCC Interconnector, linking all GCC member states. The Interconnector took some time to establish. While electricity trading was one of its long-term goals, it has also been useful for ensuring security of supply, countering grid interruptions and blackouts on many occasions.
The Interconnector has also evolved over time and has seen increased electricity trade between GCC countries, a primary function of the Interconnector, which was slow to start due to various trade barriers. Learnings from the Interconnector can be considered and explored when developing a gas grid that brings similar savings and gas trade optimization in GCC and other MENA countries.

Lower oil prices due to falling demand during the COVID-19 pandemic may impact energy investments in the region. However, they also present an opportunity for GCC countries to redouble their efforts in diversifying their economies, in which natural gas can play an important role. Therefore, the coordination of natural gas development among GCC countries has never been timelier. 


\section{Background to the Workshop}

APSARC held a virtual workshop in partnership with Khalifa University and

the International Association for Energy Economics on June 22-23, 2020, to explore the opportunities and challenges of expanding the natural gas grids of Gulf Cooperation Council (GCC) countries. Natural gas has been instrumental in meeting the growing power demand in GCC countries and establishing industrial bases that have contributed to their economic growth. Within the last decade, regional gas demand has grown by 100 billion cubic meters, placing GCC countries among the largest gas consumers per capita globally. After the significant drop in oil prices in 2014-15, there was an apparent shift by GCC members to increase their gas utilization, setting ambitious targets for the development of their abundant, non-associated gas reserves. So far, these gas strategies have been set by individual countries. However, stronger cooperation among GCC countries can foster a more efficient monetization of their gas resources. In the past, they have pursued joint infrastructure projects to promote regional integration, successfully forming a regional power grid as a result. This workshop brought together regional and international stakeholders to discuss current strategies for developing the GCC's existing gas markets, the prospects for a GCC-wide gas grid, and how it could be integrated into the energy markets of non-GCC countries. The workshop gathered a number of global experts from industry, academia, and the investment community to discuss experiences from other regions and the requirements for accelerating regional gas integration. 


\section{Demand Uncertainty in the Middle East, But With Upside Risk}

B etween 2000 and 2014, demand for natural gas in the Middle East grew significantly because of population and economic growth. Policies supporting increased industrialization to further boost economic growth and welfare drove gas-intensive industries. While industrialization and diversification efforts are still part of the region's future development plans, there is much uncertainty around the future growth of natural gas compared with its historical trend. This uncertainty mainly stems from three important factors that emerged following the drop in oil prices in mid-2014.

The first is the slower pace of economic activity after the drop in oil prices in 2014.

The second factor is the higher domestic gas prices following energy price reforms. The low, administered gas prices in the region that were intended to drive industrialization are now increasing and, in some cases, reflecting their full costs. This is driving efficiency in generation, building codes and energy use.

Third, the share of alternative energy, including renewable energy, nuclear and clean coal, is expected to increase.

While gas may be needed to balance the grid and manage renewable energy variability, battery technologies are also improving and may step in to take that role. However, some electricity utilities believe battery storage is not yet economically viable and that gas will play a crucial role in balancing the grid. Utility-scale battery storage is available but not for long durations. Even when it is available, its costs remain high, and so it is not yet a solution for a 24-hour electricity supply. Likewise, the cost of electricity from a concentrated solar power plant, which uses thermal energy storage, is currently more than the cost of running a baseload or mid-merit dispatch natural gas plant. With gas priced at $\$ 4$ per million British thermal units (MMBtu), a baseload combined-cycle gas turbine plant can cover its costs and generate a reasonable profit, even at low utilization ( $67 \%$ capacity). This cost differential is expected to last for the foreseeable future, which makes the current and near-term optimal power generation mix solar and wind, with the remaining power demand met by gas, especially in the GCC and the Middle East more broadly.

There are still areas where gas demand could increase significantly, especially in power generation, where there is still a significant amount of liquid fuel being used. Phasing out oil use in the power sector could add around 100 billion cubic meters $(\mathrm{bcm})$ of Middle Eastern gas demand by 2035. Even with oil priced at just $\$ 30$ per barrel, the cost of oil-fueled power generation is still higher than that of gas. This, coupled with the need to reduce the carbon content of power generation, is why the Kingdom of Saudi Arabia has already taken the policy decision to shut down oil-fueled power plants, estimated at just under 40 gigawatts (GW), by 2030. There is also an expectation of a strong shift in gas demand from the power sector to the industrial sector, as economic diversification efforts by some governments in the region start to gather momentum. New markets for gas, such as liquefied natural gas (LNG) for bunkering, also offer opportunities. Both the United Arab Emirates (UAE) and Oman have plans to make LNG bunkering available at their ports. Other nascent demand for natural gas includes the production of blue hydrogen (hydrogen generated from steam methane reforming) and carbon capture. 


\section{Strong Gas Supply Developments in the GCC}

The COVID-19 pandemic has caused an unprecedented fall in demand for oil and gas globally, which has led to major setbacks in energy investments. The International Energy Agency expects capital investments in oil and gas to drop by $32 \%$ in 2020 relative to 2019 levels. However, some players in the banking and investment community are showing signs of optimism around gas investments in the MENA region. The gas sector is the only sector in the region that is expected to have an increase in investment over the next five years, increasing by roughly $\$ 28$ billion over the next five years. The enthusiasm for investing in the sector is related to the role that gas can play in the region's ongoing economic diversification.

At the beginning of the century, gas production in the GCC grew rapidly. However, most of this growth was concentrated in Qatar's investments in its LNG export capacity, which peaked around 2013. Regional projected gas production growth to the end of the decade, however, expected to exceed 100 bcm, will be more evenly distributed among Saudi Arabia, Qatar, the UAE and Oman (Figure 1).

Figure 1. GCC natural gas production growth.

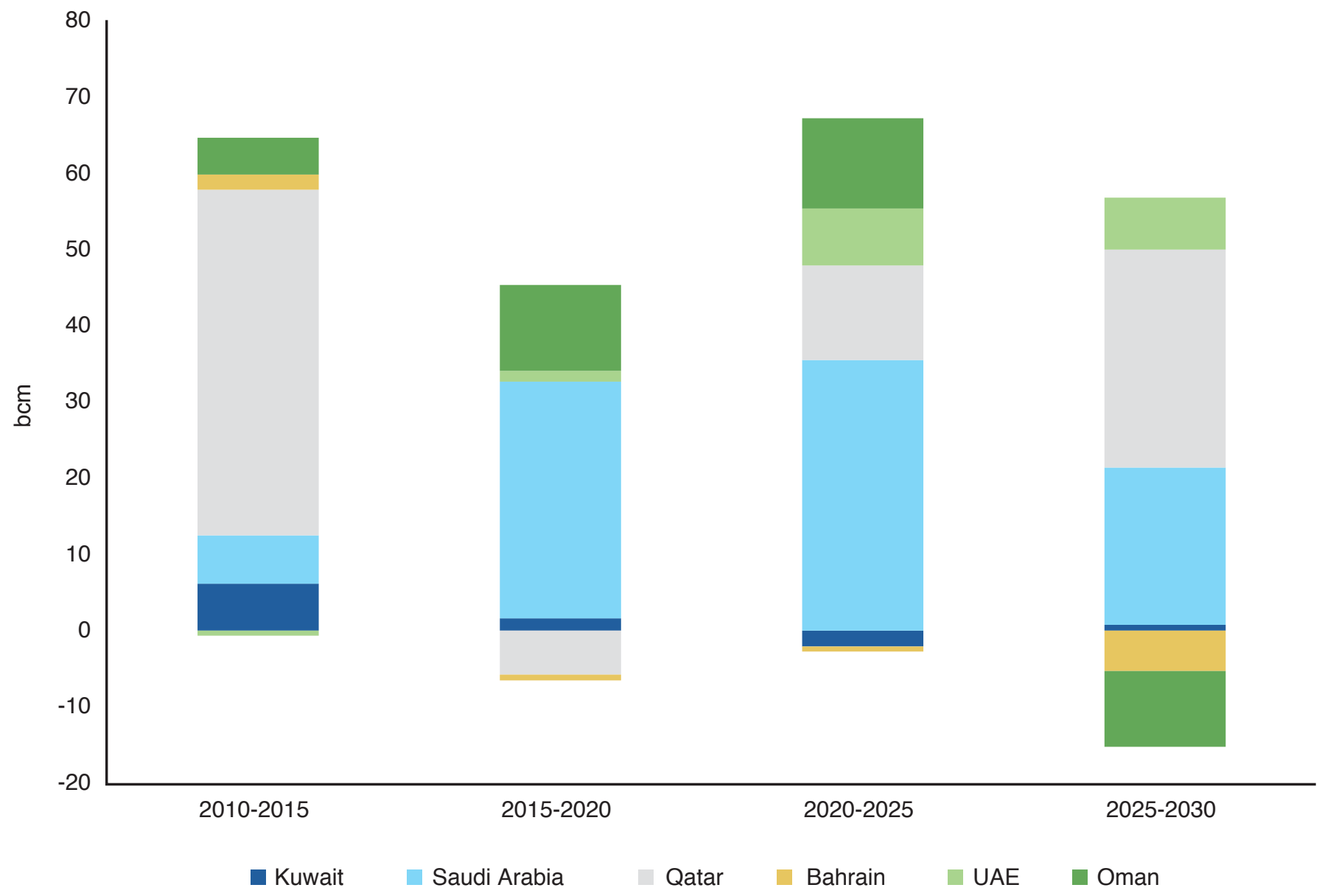

Source: Rystad Energy. 
While some of this gas will meet domestic demand, a significant portion is going to be sold on international markets. Asia has the highest regional gas consumption, and it will continue to have significant gas demand. Seventy-five percent of exported LNG goes to Asian markets. GCC countries, particularly Qatar, will continue to be important suppliers of LNG to Asian markets.
Asian countries, particularly Japan, are also taking steps toward developing a hydrogen economy as climate awareness increases. There is an opportunity for gas to be converted to blue hydrogen, which is currently less expensive than green hydrogen (hydrogen produced from the renewable-powered electrolysis of water). 


\section{Drivers for Regional Gas Integration and Overcoming Challenges}

$\mathrm{T}$ here are many advantages to regional gas integration among GCC countries, including energy security, boosting economic diversification efforts, and improving the overall efficiency of the regional energy system. However, the existing barriers to trade need to be addressed if a cross-border gas grid is to be realized. An integrated market price mechanism and gas accessibility are among the most important factors in enabling regional gas market integration. The former is tied to regulatory structures, while the latter is tied to geopolitics.

The rise of a cost-effective and efficient international LNG market has given GCC countries, and those in other regions, an alternative to domestic or regional gas production and trade. Kuwait and Bahrain, for example, have committed to building out their regasification infrastructure. Other countries, such as those of the Association of Southeast Asian Nations (ASEAN), have been considering regional gas sector integration for the last 20 years. Although significant efforts have been made in this regard, social, economic and political hurdles have led ASEAN countries to focus on LNG imports rather than regional gas trade. For the GCC, a counterfactual simulation of KAPSARC's energy model has shown that, with current gas pricing policies, roughly $\$ 400$ million could be gained if a pan-GCC gas grid had been available in 2018. The gains would have been driven by substituting regional LNG with pipeline trade at a lower supply cost. This would have provided efficiency gains in power and water generation and have allowed for gas to be burned for power generation rather than oil that could have otherwise been exported. The model has also shown that an integrated pipeline across all GCC countries can enable more trade through the existing GCC electric power Interconnector.
The GCCIA is an example of how regional collaboration can bring benefits to each participating country. Currently the GCC countries are enjoying combined economic savings of around $\$ 200-\$ 300$ million annually from using the GCC power grid. But these benefits were not realized overnight - it took a while for the GCCIA to be established. The initial techno-economic feasibility study for the project was completed in 1990, and the first phase of the connection, connecting four countries (Kuwait, Saudi Arabia, Bahrain and Qatar), did not happen until 2009. Only in 2011 were all six GCC countries connected. Until now, the grid has been mostly utilized to ensure security of supply, countering grid interruptions and potential blackouts. In late 2018, the GCCIA launched a GCC electricity market exchange platform for electricity spot market trading. The platform is expected to offer a variety of trading features such as day-ahead trading, intraday trading, and the virtual facilitation of bilateral agreements.

Similarly, an integrated gas pipeline grid in the GCC, if ultimately realized, will take time. Natural gas trade in the United States in the 1970s and the 1980s was largely set up as bilateral take-or-pay agreements between suppliers and consumers. As the market evolved and improvements in the regulatory architecture were made, competition in the gas industry emerged and provided a significant impetus for the development of the North American gas grid. The grid went from being a large trunk connecting large producers and consumers to a feeder of competitive nodes consisting of local distribution pipeline networks.

There are intersections between energy market development in the GCC and the domestic use of natural gas that can help in the development of a GCC gas grid. Particularly important is linking the 
region's natural gas development with industrial and electricity market policies, as this could create demand pull, especially in a low oil price environment. In addition, non-commercial factors are important. Political cooperation between GCC countries is important in enabling such an endeavor. Nonetheless, when an economic opportunity is presented, such as in the current environment of resource abundance, politics may take a back seat to realize the opportunities presented. 


\section{About the Workshop}

KAPSARC organized a virtual workshop, in partnership with Khalifa University and the International Association for Energy Economics, to discuss the opportunities and challenges of natural gas trade and infrastructure in the GCC. The workshop gathered more than 20 experts in a virtual roundtable spanning many areas of expertise, including industry, academia and financial institutions

\section{List of participants}

Kenneth Medlock - Fellow and Senior Director, Baker Institute, Rice University

\section{Bertrand Williams-Rioux - Research Fellow,} KAPSARC

David Williams - President, International Association for Energy Economics

Yukari Yamashita - Director, The Institute of Energy Economics Japan

Steve Griffiths - SVP Research \& Development, Khalifa University

Peter Hartley - Professor, Rice University

Fahad Alturki - VP Research, KAPSARC

Mostefa Ouki - Senior Research Fellow, Oxford Institute for Energy Studies

Robin Mills - CEO, Qamar Energy

Masakazu Toyoda - CEO and Chairman, The Institute of Energy Economics Japan

Christof Rühl - Senior Research Scholar, Center on Global Energy Policy at Columbia University

Kaushik Deb - Research Fellow and Interim Director, KAPSARC

Rami Shabaneh - Senior Research Associate, KAPSARC

Ahmed Ali Al-Ebrahim - CEO, GCCIA
Adam Sieminski - President, KAPSARC

Benjamin Schlesinger - President, Benjamin Schlesinger and Associates

Carlo Andrea Bollino - Professor, University of Perugia

Leila Benali - Chief Economist, APICORP

Tilak Doshi - Visiting Senior Research Fellow, Middle East Institute

Anne-Sophie Corbeau - Head of Gas Analysis, BP

Paddy Padmanathan - CEO, Acwa Power 


\section{Notes}

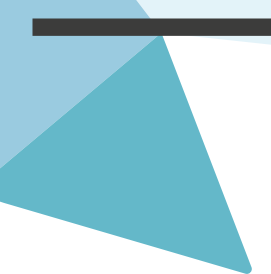


Notes

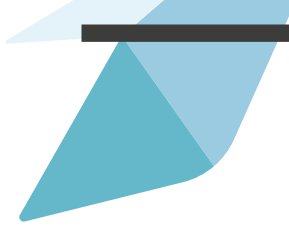




\section{About the Team}

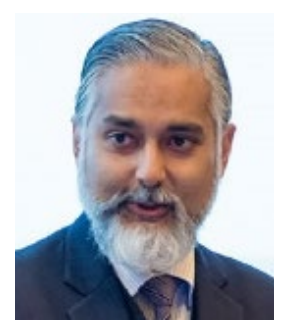

\section{Kaushik Deb}

Kaushik is a research fellow in the Markets and Industrial Development program. He is an applied economist who previously worked in the Economics team at BP, leading the analysis of the global natural gas markets and macroeconomic developments in the Asia Pacific region. His earlier roles include policy research and advocacy on infrastructure and environmental economics issues at IDFC. Kaushik also guided and implemented research in applied economics at TERI University, and was the program director of the university's MBA programs.

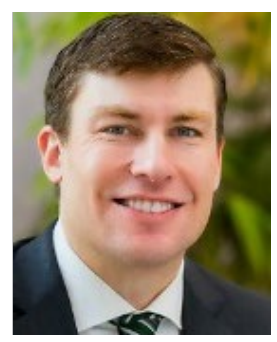

\section{Steve Griffiths}

Steve is Senior Vice President, Research and Development and Professor of Practice at Khalifa University of Science and Technology in the UAE. He specializes in energy system policy and strategy with a particular focus on the Middle East and North Africa region. He holds a Ph.D. in Chemical Engineering from the Massachusetts Institute of Technology (MIT) and an MBA from the MIT Sloan School of Management.

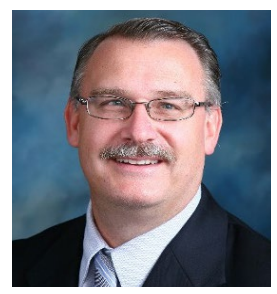

\section{David Williams}

David Williams is, since 1992, Executive Director of the International Association for Energy Economics (IAEE) and since 1994, Executive Director of the United States Association for Energy Economics (USAEE). He is managing partner of Administrative Management Service, a full-service association and conference management company.

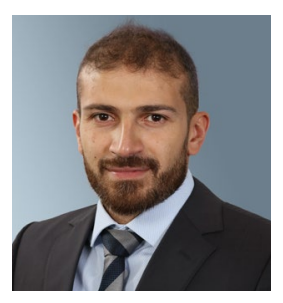

\section{Rami Shabaneh}

Rami Shabaneh is a senior research associate with a focus on global gas and liquids markets. Rami has over 13 years of research and industry experience analyzing energy markets and energy policy. Before joining KAPSARC, Rami worked at Cenovus Energy as a market fundamentals analyst, providing analytic support on specific issues affecting North American gas, natural gas liquids and condensate markets. His work informed the company's hedging strategies. Before working at Cenovus Energy, Rami spent three years as an integral member of the fuels and power research team at the Canadian Energy Research Institute. $\mathrm{He}$ holds an M.Sc. in sustainable energy development from the University of Calgary.

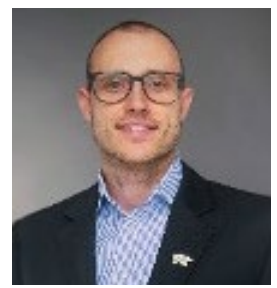

\section{Bertrand Williams-Rioux}

Bertrand is a KAPSARC Research Fellow specializing in energy market design and energy systems modeling. He holds an M.S. degree from KAUST with a specialization in computational fluid dynamics, and an M.S. in digital currency from the University of Nicosia. 


\section{About the Project}

Natural gas has been identified as a key component in enabling the diversification efforts and increasing industrialization in the GCC. After the significant drop in oil prices in 2014-15, there was an apparent shift by GCC countries to increase their gas utilization, with many setting ambitious targets for the development of their abundant non-associated gas reserves. This project aims to identify opportunities for and the challenges of gas development and coordination in Saudi Arabia and the rest of the GCC. 
INAPSARC

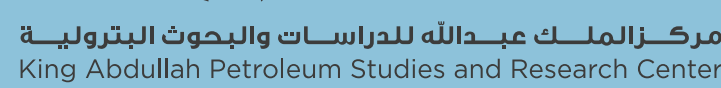

www.kapsarc.org 